\title{
PERBEDAAN FREKUENSI MENYUSU PADA BAYI DI BPM MISNI HERAWATI PALEMBANG TAHUN 2019
}

\author{
Nurbaity ${ }^{1}$, Dedeh Sumiati ${ }^{2}$ \\ Program Studi DIII Kebidanan STIKES Mitra Adiguna Palembang. \\ Komplek Kenten Permai Blok J No 9-12 Bukit Sangkal Palembang 30114 \\ Email : nurbaity260576@gmail.com
}

\begin{abstract}
Abstrak
Dinas Kesehatan Kota Palembang cakupan pemberian ASI eksklusif, pada tahun 2015 sebesar 72,91\%, pada tahun 2016 sebesar 68,6 dan tahun pada tahun 2017 sebesar 72,76\%. Kesimpulan permasalahan dalam pemberian ASI ada pada praktek menyusui yang masih buruk termasuk frekuensi menyusu. Tujuan penelitian ini adalah untuk mengetahui perbedaan pijat bayi terhadap frekuensi menyusu pada bayi di wilayah kerja BPM Misni Herawati Palembang Tahun 2019. Ruang lingkup penelitian ini ditujukan kepada bayi berusia $2-6$ bulan yang mendapatkan ASI eksklusif, dipijat dan tidak dipijat. Metode yang digunakan posttest only with control group design. Hasil yang diperoleh analisi sbivariat hasil uji Mann Whitney test didapatkan nilai value 0,000 <0,05, disimpulkan ada perbedaan pijat bayi terhadap frekuensi menyusu pada bayi di wilayah kerja BPM Misni Herawati Palembang Tahun 2019. Saran kepada tenaga kesehatan khususnya bidan dapat mensosialisasikan pijat bayi pada ibu-ibu yang mempunyai bayi dan dapat mengadakan pelatihan cara melakukan pijat bayi untuk ibu-ibu yang mempunyai bayi.
\end{abstract}

Kata kunci : Pijat bayi, frekuensi menyusu

\begin{abstract}
The Palembang City Health Office, the coverage of exclusive breastfeeding, in 2015 was $72.91 \%$, in 2016 it was 68.6 and in 2017 it was $72.76 \%$. Conclusion, the problem in breastfeeding is the poor breastfeeding practice, including the frequency of breastfeeding. The purpose of this study was to determine the differences in infant massage on the frequency of breastfeeding in infants in the working area of BPM MisniHerawati Palembang in 2019. The scope of this study was aimed at infants aged 2-6 months who received exclusive breastfeeding, massaged and not massaged. The method used was posttest only with control group design. The results obtained by the bivariate analysis of the results of the Mann Whitney test obtained a value of $0.000<0.05$, it was concluded that there were differences in infant massage on the frequency of breastfeeding in infants in the work area of BPM MisniHerawati Palembang in 2019. Suggestions to health workers, especially midwives, can socialize baby massage at mothers who have babies and can provide training on how to do baby massage for mothers who have babies.
\end{abstract}

Key words: Infant massage, breastfeeding frequency 


\section{PENDAHULUAN}

Salah satu dari pemberian ASI dituangkan dalam Undang-Undang Kesehatan No. 36 tahun 2009 tentang kesehatan yang diantaranya memuat pasal sebagai berikut, pasal 128 , ayat 1 adalah setiap bayi berhak mendapatkan air susu ibu eksklusif sejak dilahirkan selama 6 (enam) bulan, kecuali atas indikasi medis (Astutik, 2014).

Berdasarkan data Riset Kesehatan Dasar tahun 2018, proporsi pola pemberian ASI (menyusui) secara eksklusif di Indonesia pada bayi umur 0-5 bulan sebesar 37,3\%, dengan karakteristik tempat tinggal di Perkotaan sebesar 40,7\% dan Perdesaan sebesar 33,6\% (Riskesdas, 2018).

Sementara berdasarkan data dari Profil Kesehatan Indonesia Tahun 2017, secara nasional, cakupan bayi mendapat ASI eksklusif sebesar 61,33\% dan cakupan pemberian ASI eksklusif di Provinsi Sumatera Selatan sebesar 60,36 (Kemenkes RI, 2018).

Selanjutnya data dariDinas Kesehatan Kota Palembang cakupan pemberian ASI eksklusif, pada tahun 2015 sebesar 72,91\%, pada tahun 2016 sebesar 68,6 dan tahun pada tahun 2017 sebesar 72,76\% (Seksi Kesehatan Dasar, 2017).

Permasalahan dalam pemberian ASI antara lain, masalah internal yaitu masalah fisik dimana seorang ibu yang sehat adalah kunci untuk keberhasilan menyusui, psikologis karena kepercayaan diri adalah factor kunci untuk ibu menyusui, inisiasi menyusui yang tertunda terbukti erat terkait durasi menyusui yang singkat, pekerjaan fisik menguras tenaga dan menurunkan status gizi ibu akhirnya kurang sehat untuk menyusui, pendidikan format tampak tidak berkaitan dengan kebiasaan menyusui dan masalah eksternal yaitu masalah keluarga dimana keterlibatan ayah adalah salah satu factor kunci dalam mendukung praktek menyusui, ketahanan pangan merupakan masalah karena nurtisi penting untuk mereka dalam masa menyusui, wilayah geografis menunjukkan kecendungan ibu di kota melahirkan di rumah sakit, klinik diperkenalkan dengan susu formula, peran media dapat memainkan dua peran yang berbeda dalam mensukseskan ASI eksklusif dan di sisi lain digunakan secara habis-habisan mengiklankan susu formula, air, kebersihan dan sanitasi dapat menjadi masalah bagi ibu untuk menyusui, professional kesehatan sangat besar dalam menganti ASI menjadi susu formula, kemiskinan terkait dengan gizi ibu menyusui, keyakinan dan praktek budaya berkaitan dengan makanan prelakteal dengan menggunakan madu, air, air dengan gula, teh dan pisang, keterlibatan pemerintah untuk menbangun situasi yang kondusif dalam menyusui. Kesimpulannya ada pada praktek menyusui yang masih buruk termasuk frekuensi menyusu (Kadir, 2014).

Salah satu upaya untuk meningkatkan frekuensi menyusu ASI pada bayi adalah dengan cara pijat bayi rutin. Manfaat pijat bagi bayi adalah memaksimalkan aktivitas nervus vagus dan penyerapan makanan akan lebih baik menjadikan bayi cepat lapar dan lebih sering menyusu ibunya (Nasiroh, 2016).

Pijat bayi merupakan tradisi lama yang digali kembali dengan sentuhan ilmu kesehatan dan tinjauan ilmiah yang bersumber dari penelitianpenelitian para ahli neonatologi, saraf, dan psikologi anak. Beberapa dokter dari Eropa dan Amerika telah marak mempublikasikan manfaat pijat bagi kesehatan bayi dan kebahagian seluruh keluarga (Subaktidkk, 2018).

Pijat bayi akan merangsang peningkatan aktivitas nervus vagus yang akan menyebabkan penyerapan lebih baik pada system pencernaan, 
sehingga bayi akan lebih cepat lapar dan frekuensi menyusu bayi akan semakin sering. Selain itu terdapat berbagai manfaat pijat bayi bagi bayi antara lain meningkatkan berat badan karena bayi lebih sering menyusu, meningkatkan pertumbuhan, meningkatkan daya tahan tubuh, membuat bayi tidur lebih lelap, dan dapat meningkatkan produksi ASI (Luize dalam Nasiroh, 2016).

Satu hal yang sangat menarik pada penelitian tentang pemijatan bayi adalah penelitian tentang mekanika dasar pemijatan. Mekanisme dasar dari pijat bayi belum banyak diketahui, walaupun demikian, saat ini pakar sudah mempunyai beberapa teori tentang mekanisme ini serta mulai menemukan jawabannya. Diajukan beberapa mekanisme untuk menolong menerangkan mekanisme dasar pijat bayi antara lain, aktivitas nervus vagus meningkatkan volume ASI. Penyerapan makanan menjadi lebih baik karena peningkatan aktivitas nervus vagus menyebabkan bayi cepat lapar sehingga akan lebih sering menyusu pada ibunya (Roesli, 2016).

Berdasarkan data dari BPM Misni Herawati Palembang, jumlah bayi yang mendapatkan ASI eksklusif, pada tahun 2016 sekitar 418 bayi (80\%), tahun 2017 sekitar 565 bayi (82\%) dan tahun 2018 sekitar 475 bayi $(85 \%)$.

Dari uraian diatas peneliti tertarik untuk melakukan penelitian yang berjudul "Perbedaan Frekuensi Menyusu Pada Bayi yang Dipijat dan Tidak Dipijat di Wilayah Kerja BPM Misni Herawati Palembang Tahun 2019”

\section{METODE PENELITIAN}

\section{JenisPenelitian}

Jenis penelitian eksperimental menggunakan rancangan independent samples $t$ test. Penelitian ini dilakukan terhadap dua kelompok yang tidak berpasangan yaitu kelompok bayi yang dipijat dan tidak dipijat. Pada bayi yang tidak dipijat frekuensi menyusu langsung ditanyakan kepada ibu dari bayi dan dicatat pada lembar observasi, sedangkan pada bayi yang dipijat, bila belum pernah dipijat maka dilakukan pemijatan terlebih dahulu sebanyak 4 kali dengan perincian 1 minggu sekali, setelah pemijatan keempat kali, kemudian frekuensi menyusu berdasarkan pengakuan ibu dari bayi dicatatkan di lembar observasi.

\section{Waktu dan Tempat Penelitian}

Penelitian dilakukan pada bulan November 2019 di BPM Misni Herawati Palembang

\section{Target/Subjek Penelitian}

Subyek penelitian ini ditujukan kepada bayi berusia $2-6$ bulan yang mendapatkan ASI eksklusif, dipijat dan tidak dipijat, Populasi pada penelitian ini adalah keseluruhan bayi berusia 2-6 bulan yang dating ke BPM Misni Herawati Palembang saat penelitian atau bertempat tinggal di wilayah kerja BPM tersebut. Sampel penelitian ini adalah berjumlah 30 orang terdiri dari 15 bayi kelompok kontrol (tidak dipijat) dan 15 bayi kelompok eksperimen (dipijat) di BPM Misni Herawati Palembang. Teknik pengambilan sampel secara non probability purposive sampling

\section{Prosedur}

Penelitian ini dilakukan terhadap dua kelompok yang tidak berpasangan yaitu kelompok bayi yang dipijat dan tidak dipijat. Pada bayi yang tidak dipijat frekuensi menyusu langsung ditanyakan kepada ibu dari bayi dan dicatat pada lembar observasi, sedangkan pada bayi 
yang dipijat, bila belum pernah dipijat maka dilakukan pemijatan terlebih dahulu sebanyak 4 kali dengan perincian 1 minggu sekali, setelah pemijatan keempat kali, kemudian frekuensi menyusu berdasarkan pengakuan ibu dari bayi dicatatkan di lembar observasi.

Data, Intrumen, dan Teknik Pengumpulan Data

Metode pengumpulan data dilakukan secara manual, menggunakan lembar observasi sebagai sumber data primer.

\section{Teknik Analisis Data}

Analisis data yang digunakan untuk melihat distribusi frekuensi dari variabel dependen (frekuensi menyusu) dan variabel independen (pijat bayi). Selanjutnya untuk mengetahui perbedaan menggunakan uji statistic Independent Samples t Test dengan tingkat kemaknaan alpha 0,05 bila data terdistribusi normal dan Mann Whitney test bila data tidak terdistribusi normal dengan ketentuan jika $p$ value $<0,05$ berarti ada perbedaan dan jika $p$ value $\geq 0,05$ berarti tidak ada perbedaan (Dahlan, 2013). Uji Mann Whitney test adalah uji komparatif variable numeric distribusi tidak normal, dua kelompok tidak berpasangan (Dahlan, 2013). Berdasarkan ketentuan diatas maka pada penelitian ini, jika hasil analisis didapatkan $p$ value $<0,05$ berarti ada perbedaan pijat bayi terhadap frekuensi menyusu pada bayi dan jika $p$ value $\geq 0,05$ berarti tidak ada perbedaan pijat bayi terhadap frekuensi menyusu pada bayi.

\section{HASIL PENELITIAN DAN} PEMBAHASAN

Analisis univariat pada penelitian ini dilakukan pada tiap variable dari hasil penelitian yaitu variabel dependen (frekuensi menyusu) dan variabel independen (pijat bayi) dalam table frekuensi dan persentase.

1. Frekuensi Menyusu

Pada penelitian ini variabel frekuensi menyusu, hasil ukurnya adalah berdasarkan jumlah menyusu bayi selama 24 jam. Untuk lebih jelas terlihat pada Tabel 1 dibawah ini.

Tabel 1 Distribusi Frekuensi

Responden Berdasarkan Frekuensi Menyusu

\begin{tabular}{|c|c|c|c|c|c|c|c|}
\hline \multirow[t]{2}{*}{$\begin{array}{l}\mathbf{N} \\
\mathbf{0}\end{array}$} & \multirow{2}{*}{$\begin{array}{c}\text { Frekuensi } \\
\text { Menyusu } \\
\text { (dalam 24 } \\
\text { jam) }\end{array}$} & \multicolumn{2}{|c|}{ Bayi Dipijat } & \multicolumn{2}{|c|}{$\begin{array}{c}\text { Bayi Tidak } \\
\text { Dipijat }\end{array}$} & \multicolumn{2}{|c|}{ Total } \\
\hline & & $\mathbf{f}$ & $\%$ & $\mathbf{f}$ & $\%$ & $\mathbf{f}$ & $\%$ \\
\hline 1 & $8-10$ & 0 & 0 & 8 & 53 & 8 & 27 \\
\hline 2 & $11-13$ & 8 & 53 & 7 & 47 & 15 & 50 \\
\hline 3 & $14-16$ & 7 & 47 & 0 & 0 & 7 & 23 \\
\hline & & 15 & 100 & 15 & 100 & 30 & 10 \\
\hline
\end{tabular}

Dari Tabel 1 dapat dilihat bahwa sebagian besar frekuensi menyusu pada interval 11-13 kali dalam 24 jam berjumlah 15 orang $(50 \%)$ dengan perincian bayi yang dipijat 8 orang $(53,3 \%)$ dan tidak dipijat 7 orang $(46,7)$.

\section{Pijat Bayi}

Pada penelitian ini variabel pijat bayi dibagi menjadi 2 kategori yaitu ya, bila bayi diberikan perlakuan pemijatan dan tidak, bila bayi tidak diberikan perlakuan pemijatan. Untuk lebih jelas terlihat pada Tabel 2 dibawah ini. 
Tabel 2 Distribusi Frekuensi Responden Berdasarkan Pijat Bayi

\begin{tabular}{clcc}
\hline No & Pijat Bayi & $\begin{array}{c}\text { Frekuensi } \\
(\mathbf{f})\end{array}$ & $\begin{array}{c}\text { Persentasi } \\
(\boldsymbol{\%})\end{array}$ \\
\hline 1 & Ya & 15 & 50 \\
\hline 2 & Tidak & 15 & 50 \\
\hline & & 30 & 100 \\
\hline
\end{tabular}

Dari Tabel 2 dapat dilihat bahwa bayi yang dipijat dan tidak dipijat sama banyaknya yaitu masing-masing sebanyak 15 orang $(50 \%)$.

\section{Analisis Bivariat}

Tabel 3 Uji Normalitas Frekuensi Menyusu

\begin{tabular}{clccc}
\hline No & Variabel & $\begin{array}{c}\text { Shapiro- } \\
\text { Wilk }\end{array}$ & $\boldsymbol{p}$ & Status \\
\hline 1 & Frekuensi & 0,774 & 0,002 & Tidak \\
& $\begin{array}{l}\text { menyusu } \\
\text { bayi yang } \\
\text { dipijat }\end{array}$ & & & \\
\hline 2 & Frekuensi & 0,761 & 0,001 & Tidak \\
& menyusu \\
& bayi & & & normal \\
& $\begin{array}{l}\text { yangtidak } \\
\text { dipijat }\end{array}$ & & & \\
\hline
\end{tabular}

Berdasarkan tabel 3 di atas, diketahui hasil uji normalitas untuk frekuensi menyusu bayi yang dipijat dan tidak dipijat, mendapatkan nilai $p$ $=(0,002$ dan 0,001) < 0,05 , maka distribusi data dinyatakan tidak normal.

Selanjutnya analisis bivariat dilakukan untuk melihat perbedaan pijat bayi terhadap frekuensi menyusu pada bayi di BPM Misni Herawati Palembang tahun 2019, menggunakan uji Mann Whitney test dengan ketentuan jika $p$ value $<0,05$ berarti ada perbedaan dan jika $p$ value $\geq 0,05$ berarti tidak ada perbedaan.
Tabel 4 Hasil Analisis Uji Mann Whitney test dengan Penambahan Informasi Rerata dan Simpang Baku Frekuensi Menyusu Berdasarkan Pijat Bayi

\begin{tabular}{|c|c|c|c|c|c|}
\hline- & $\mathbf{n}$ & $\begin{array}{c}\text { Median } \\
\text { (minimum- } \\
\text { maksimum) }\end{array}$ & $\begin{array}{c}\text { Rerata } \\
\pm \text { s.b }\end{array}$ & $\begin{array}{l}\text { Mean } \\
\text { Rank }\end{array}$ & $\begin{array}{c}p \\
\text { value }\end{array}$ \\
\hline $\begin{array}{l}\text { Frekuensi } \\
\text { menyusu } \\
\text { bayi yang } \\
\text { dipijat }\end{array}$ & 15 & $\begin{array}{c}12 \\
(12-16)\end{array}$ & $\begin{array}{c}13,33 \\
\pm \\
1,589\end{array}$ & 21,13 & 0,000 \\
\hline $\begin{array}{l}\text { Frekuensi } \\
\text { menyusubayi } \\
\text { yang tidak } \\
\text { dipijat }\end{array}$ & 15 & $\begin{array}{c}10 \\
(8-12)\end{array}$ & $\begin{array}{l}10,80 \\
\pm \\
1,265\end{array}$ & 9,87 & \\
\hline
\end{tabular}

Dari Tabel 4 dapat dilihat bahwa rata-rata frekuensi menyusu yang melakukan pijat bayi adalah 13,33 dengan standar deviasi 1,589, sedangkan untuk rata-rata frekuensi menyusu tidak yang melakukan pijat bayi adalah 10,80 dengan standar deviasi 1,265. Hasil uji statistic didapatkan nilai value $0,000<0,05$, artinya ada perbedaan pijat bayi terhadap frekuensi menyusu pada bayi di wilayah kerja BPM Misni Herawati Palembang Tahun 2019.

\section{Pembahasan}

Berdasarkan hasil penelitian pada tabel 1 diketahui sebagian besar frekuensi menyusu pada interval 11-13 kali dalam 24 jam berjumlah 15 orang (50\%) dengan perincian bayi yang dipijat 8 orang $(53,3 \%)$ dan tidak dipijat 7 orang $(46,7)$ dan pada tabel 2 diketahui bayi yang dipijat dan tidak dipijat sama banyaknya yaitu masingmasing sebanyak 15 orang $(50 \%)$.

Selanjutnya pada tabel 3 diketahui rata-rata frekuensi menyusu yang melakukan pijat bayi adalah 13,33, sedangkan untuk rata-rata frekuensi menyusu tidak yang 
melakukan pijat bayi adalah 10,80, terlihat frekuensi menyusu bayi yang dipijat lebih tinggi dari pada frekuensi menyusu, sehingga dapat disimpulkan pijat bayi dapat meningkatkan frekuensi menyusu pada bayi. Hasil uji Mann Whitney test didapatkan nilai value $0,000<0,05$, artinya ada perbedaan pijat bayi terhadap frekuensi menyusu pada bayi di wilayah kerja BPM Misni Herawati Palembang Tahun 2019.

Hasil penelitian sesuai dengan pernyataan Surbakti dkk (2018), pijat bayi menyebabkan bayi lebih rileks dan dapat beristirahat dengan efektif. Bayi yang tidur dengan efektif ketika bangun akan membawa energi cukup untuk beraktivitas. Dengan aktivitas yang optimal, bayi akan cepat lapar sehingga nafsu makannya meningkat. Peningkatan nafsu makan ini juga ditambah dengan peningkatan aktivitas nervus vagus/ saraf pengembara (sistem saraf otak yang bekerja untuk daerah leher ke bawah sampai dada dan rongga perut) dalam menggerakan sel paristaltik (sel di saluran pencernaan yang menggerakkan dalam saluran pencernaan) untuk mendorong makanan ke saluran pencernaan. Dengan demikian, bayi lebih cepat lapar atau ingin makan karena pencernaannya semakin lancar

Hasil penelitian ini juga sesuai dengan pernyataan Fitriahadi (2016), dengan diberikan pijat bayi aktivitas nervus vagus mempengaruhi mekanisme penyerapan makanan pada bayi yang dipijat mengalami peningkatan tonus nervus vagus yang akan menyebabkan peningkatan enzim penyerapan gastrin dan insulin sehingga menyebabkan penyerapan makan menjadi lebih baik dan meningkatkan berat badan bayi. Aktivitas nervus bagus meningkatkan volume ASI, penyerapan makanan menjadi lebih baik karena peningkatan aktivitas nervus vagus menyebabkan bayi cepat lapat dan akan lebih sering menyusu pada ibunya.

Hasil penelitian ini sejalan dengan hasil penelitian Farida dkk (2018), yang berjudul "Pengaruh Pijat Bayi Terhadap Peningkatan Frekuensi dan Durasi Menyusu Pada BayiUsia 1 3 Bulan". Jenis penelitian yang digunakan yaitu Quasy experimenntal (eksperimen semu), menggunakan Uji $T$ test, diperoleh data bahwa ada pengaruh antara pijat bayi dengan frekuensi menyusu pada bayi di Puskesmas Cikampek Karawang dengan nilai $p(0,000)$.

Hasil penelitian ini juga sejalan dengan hasil penelitian Fitriahadi (2016), yang berjudul "Pengaruh Pijat Terhadap Frekuensi dan Durasi Menyusu Bayi". Rancangan penelitian kuantitatif dengan metode eksperimen (quasy experimental design), dengan hasil uji statistikp value 0,03 (karena $p$ value < 0,05), maka Ho ditolak dan $\mathrm{Ha}$ diterima, artinya ada pengaruh pijat bayi terhadap frekuensi bayi di BPM Istri Utami Sleman.

Hasil penelitian ini juga sesuai dengan pernyataan Roesli (2016), fisiologi pijat bayi menyebabkan aktivitas nervus vagus meningkatkan volume ASI. Penyerapan makanan menjadi lebih baik karena peningkatan aktivitas nervus vagus menyebabkan bayi cepat lapar sehingga akan lebih sering menyusu pada ibunya

Hasil penelitian ini juga sejalan dengan hasil penelitian Nasiroh (2016), yang berjudul "Perbedaan Frekuensi Menyusu Asi Eksklusif Sebelum dan Sesudah Dilakukan Pijat Bayi”. Desain penelitian menggunakan pre eksperimental dengan pendekatan one group pretest post test. Uji perbedaan menggunakan uji $t$ dependen yaitu $\mathrm{t}$ hitung $=-7,303$ dengan $p$-value 0,000 . p-value $0,000<0,05$ maka Ho ditolak, disimpulkan ada perbedaan frekuensi menyusu ASI sebelum dan sesudah dilakukan pijat bayi di Desa Candi. 
Dari penelitian diatas dapat disimpulkan bahwa ada perbedaan pijat bayi terhadap frekuensi menyusu pada bayi di wilayah kerja BPM Misni Herawati Palembang Tahun 2019, karena bayi yang dipijat biasanya lebih rileks dan dapat beristirahat dengan efektif. Bayi yang tidur dengan efektif ketika bangun akan membawa energi cukup untuk beraktivitas. Dengan aktivitas yang optimal, bayi akan cepat lapar sehingga nafsu makannya meningkat.

\section{KESIMPULAN}

a. Dari analisis univariat distribusi frekuensi sebagian besar frekuensi menyusu pada interval 11-13 kali dalam 24 jam berjumlah 15 orang (50\%) dengan perinciaan bayi yang dipijat 8 orang $(53,3 \%)$ dan tidak dipijat 7 orang $(46,7)$

b. Dari analisis univariat distribusi frekuensi bayi yang dipijat dan tidak dipijat sama banyaknya yaitu masing-masing sebanyak 15 orang $(50 \%)$.

c. Dari analisis bivariat hasil uji normalitas untuk frekuensi menyusu bayi yang dipijat dan tidak dipijat, mendapatkan nilai $p=$ $(0,002$ dan 0,001$)<\alpha 0,05$, maka distribusi data dinyatakan tidak normal. Hasil uji Mann Whitney test didapatkan nilai value $0,000<0,05$, artinya ada perbedaan pijat bayi terhadap frekuensi menyusu pada bayi di wilayah kerja BPM Misni Herawati Palembang Tahun 2019.

\section{SARAN}

a. Bagi BPM Misni Herawati Palembang

Diharapkan kepada tenaga kesehatan khususnya bidan di BPM Misni Herawati Palembang, dapat mensosialisasikan pijat bayi pada ibu-ibu yang mempunyai bayi dan dapat mengadakan pelatihan cara melakukan pijat bayi untuk ibu-ibu yang mempunyai bayi, karena pijat bayi banyak sekali manfaatnya terutama untuk tumbuh kembang bayi.

\section{b. Bagi Institusi Pendidikan}

Agar dapat menjadi hasil penelitian ini sebagai bahan acuan dan merupakan informasi lengkap yang bermanfaat untuk menambah pengetahuan mahasiswa khususnya Program Studi Diploma III Kebidanan.

\section{c. Bagi Peneliti Yang Akan Datang}

Agar dapat menjadikan penelitian ini sebagai bahan acuan untuk meneruskan penelitian ini mengenai pijat bayi dengan variable independen yang berbeda, dimana belum sempat diteliti pada penelitian ini, sehingga penelitian ini terus berkembang dan semakin akurat hasilnya.

\section{UCAPAN TERIMA KASIH}

Penulis mengucapkan terimakasih kepada Ketua STIKES Mitra Adiguna Palembang yang telah member dukungan financial terhadap penelitian ini.

\section{DAFTAR PUSTAKA}

Astutik, Reni Yuli. 2014. Payudara Dan Laktasi. Jakarta: Salemba Medika.

Farida Y, Mardianti, Komalasari L. 2018. Pengaruh Pijat Bayi Terhadap Peningkatan Frekuensi dan Durasi Menyusu Pada Bayi Usia 1 - 3 Bulan. Jurnal Kebidanan, 7 (1), 2018.

Fitriahadi, Enny. 2016. Pengaruh Pijat Bayi Terhadap Frekuensi dan Durasi Menyusu Bayi. Jurnal Kesmas. Vol. 10. No. 2. September 2016. 
Kadir, Nuhira Abdul. 2014. Menelusuri Akar Masalah Rendahnya Persentase Pemberian ASI Eksklusif di Indonesia. Jurnal Al Hikmah Vol. XV. Nomor 1/ 2014.

Kemenkes RI. 2018. Profil Kesehatan Indonesia Tahun 2017.

Nasiroh Utia Dina, Rini Susanti dan Chichik Nirmasari. 2016. Perbedaan Frekuensi Menyusu ASI Eksklusif Sebelum dan Sesudah Dilakukan Pijat Bayi. MUSWIL IPEMI Jateng, 17 September 2016.

Riskesdas. 2018. Proporsi Pola Pemberian ASI Pada Bayi Umur 0-5 Bulan Menurut Propinsi dan Karakteristik.

Roesli, Utami. 2016. Pedoman Pijat Bayi Edisi Revisi. Depok: Trubus Agriwidya.

Seksi Kesehatan Dasar. 2017. Profil Dinas Kesehatan Palembang Tahun 2015,2016 dan 2017.

Subakti. Yazid dan Deri Rizki Anggarani. 2018. Keajaiban Pijat Bayi \& Balita. Jakarta: Kawahmedia. 